\title{
Corporate Political Strategies and Economic Performance-From the Perspective of Legitimacy
}

\author{
Yiling Yao ${ }^{1, a}$ \\ ${ }^{1}$ Archbishop Ryan High School, Hebei Province 050021, China \\ ayyao18@ryanhs.org
}

Keywords: political strategy; economic benefit; legitimacy

\begin{abstract}
In this paper, we mainly analyze the relationship between corporate political strategies, economic performance and legitimacy in depth and finally confirm that from the perspective of legitimacy, corporate political strategies can produce a positive impact on economic performance, thus promoting the sustainable development of enterprises.
\end{abstract}

\section{Introduction}

Under the concept of the rule of law, the formulation of enterprise's operation policies and regulations has broken away from the government's restrictions. Enterprises can adopt different methods to exert an influence on the formation process of policies and regulations. This process is corporate political strategies. It is far from enough to consider enterprise efficiency and performance alone, we should also take social customs, values and other factors into account. So the fact that enterprises realize economic performance through political strategy has received widespread attention.

\section{Research Design}

\section{Hypotheses}

From the perspective of legitimacy (A), in view of the relationship between corporate political strategies (B) and economic performance (C), three hypotheses were proposed in this paper:

Hypothesis 1: B and $\mathrm{C}$ were positively correlated;

Hypothesis 2: A and B were positively correlated;

Hypothesis 3: A and C were positively correlated.

\section{Sample Collection}

Our study mainly involved the level of enterprise strategies and concerned a great deal of sensitive information. So samples were derived from top and middle managers. After invalid questionnaires were eliminated, 166 valid questionnaires were obtained. From geographical distribution, most enterprises were concentrated in Hubei, Henan and Zhejiang, etc. From industry distribution, they involved multiple fields, such as telecommunications, iron and steel, etc. So sample data collected in the present study were highly representative and conformed to the requirements of study.

\section{Sample Test}

In the present study, we mainly used Cronbach's $\alpha$ for validation, to ensure the reliability of variables. In terms of validity, we mainly used the principal component analysis (PCA) for validation. In practice, political strategies were was measured. We drew on from scholar's points of view and identified two factors as relationship-oriented and transaction-oriented. The former emphasized long-term, while the latter focused on short-term goals. After verifying the two factors, the coefficients were 0.726 and 0.815 respectively, as shown in Tab. 1. 
Tab. 1 The Reliability and Validity of Corporate Political Strategies

\begin{tabular}{lcl}
\hline & Factor 1 (TRAO) & Factor 2 (RELO) \\
\hline Cronbach's $\alpha$ & 0.726 & 0.815 \\
Eigenvalue & 4.254 & 2.356 \\
Contribution Rate (\%) & 42.439 & 28.429 \\
Cumulative Contribution Rate (\%) & 42.438 & 70.869 \\
\hline
\end{tabular}

For the measurement of corporate economic performance, since it was affected by analytical hierarchy and strategic difference, in this paper, we adopted performance measurement to explore relevant indicators, so as to increase reliability. But most enterprises were in Asian countries. Combined with existing research findings, we finally chose four questions to measure economic performance, as shown in Tab. 2.

Tab. 2 The Reliability and Validity of Economic Performance

\begin{tabular}{ll}
\hline & Factor Loading \\
\hline Cronbach's $\alpha$ & 0.798 \\
Eigenvalue & 5.256 \\
Contribution Rate (\%) & 55.306 \\
Cumulative Contribution Rate (\%) & 55.306 \\
\hline
\end{tabular}

From the perspective of legitimacy, the so-called legitimacy referred to social value implied in organizational activities that was related to organizational activities. Combined with interview results, we used 8 items to measure legitimacy. The reliability test showed that the coefficient was 0.884 , as shown in Tab. 3.

Tab. 3 The Reliability and Validity of Legitimacy

\begin{tabular}{ll}
\hline & Factor Loading \\
\hline Cronbach's $\alpha$ & 0.884 \\
Eigenvalue & 6.527 \\
Contribution Rate (\%) & 41.689 \\
Cumulative Contribution Rate (\%) & 41.689 \\
\hline
\end{tabular}

\section{Empirical Analysis}

From the table of correlation coefficient (Tab. 4), it is known that relationship-oriented and transaction-oriented political strategies were closely related to economic benefits and legitimacy. They had a significant positive relationship. This result showed that corporate political strategies were conducive to the promotion of legitimacy and economic benefits [1]. Meanwhile, two kinds of political strategies influenced each other, which sufficed to prove their interplay and mutual influence.

Tab. 4 Descriptive Statistics and Coefficients

\begin{tabular}{llllllll}
\hline Variable & Mean & S.D. & 1 & 2 & 3 & 4 & 5 \\
\hline EP & 0 & 1 & & & & & \\
TRAO & 0 & 1 & $0.418^{* * *}$ & & & & \\
RELO & 0 & 1 & $0.527^{*}$ & $0.494^{* *}$ & & & \\
LEGI & 0 & 1 & $0.478^{* *}$ & $0.502^{*}$ & $0.395^{* *}$ & & \\
Enterprise Scale & 5.394 & 1.672 & 0.127 & 0.307 & $0.169^{*}$ & 0.025 & \\
Enterprise Nature & 0.552 & 0.512 & 0.315 & 0.228 & $0.357^{* *}$ & 0.119 & 0.025 \\
& & & & & & $*$ & \\
\hline
\end{tabular}

Through test, the regression model built in our study didn't involve multicollinearity, so we conducted a regression analysis on the model. The results are shown in Tab. 5. From the relationship between political strategies and economic performance, Hypothesis 1 was supported. After relationship-oriented political strategy entered the regression model, the regression coefficient was positive and consistent with the hypothesized direction. But p was less than 0.1 , so we concluded that 
transaction-oriented political strategy can improve economic benefits of enterprises, with the help of relationship-oriented political strategy.

Tab. 5 Regression Results of OLS Model

\begin{tabular}{lllllll}
\hline $\begin{array}{l}\text { Variabl } \\
\mathrm{e}\end{array}$ & B and C & \multicolumn{3}{c}{ A and B } & A and C & Overall Model \\
\hline Model & 1 & 2 & 3 & 4 & 5 & 6 \\
TRAO & $0.189^{* *}$ & 0.118 & $0.238^{* *}$ & 0.217 & & 0.408 \\
RELO & $(0.094)$ & $(0.125)$ & $(0.196)$ & $(0.175)$ & & $(0.239)$ \\
LEGI & & $0.308^{* *}$ & & $0.278^{* *}$ & $0.398^{* *}$ & 0.206 \\
SIZE & & $(0.235)$ & & $(0.134)$ & $(0.239)$ & $(0.095)$ \\
\hline
\end{tabular}

As for the relationship between political strategy and legitimacy, from the data in the table, Hypothesis 2 was supported. For Model 4, both relationship-oriented and transaction-oriented political strategies had a significant impact on the promotion of legitimacy. The regression coefficient of transaction-oriented political strategy was positive. This was consistent with our hypothesis, too.

Besides, according to our analysis of the relationship between legitimacy and economic performance, Hypothesis 3 was supported. With respect to the validation of legitimacy in terms of political strategy and economic performance, from the regression result in Model 6, we can see that both the regression coefficients of relationship-oriented and transaction-oriented political strategies were positive. Generally speaking, the formulation and implementation of corporate political strategies can largely improve their legitimacy, standardize the work of enterprises and thus improve corporate economic benefits. So for corporate development, legitimacy served as a connecting link between the superior and inferior.

Relationship-oriented and transaction-oriented political strategies can largely improve corporate economic performance, provided that legitimacy was ignored [2]. Therefore, in the process of development, enterprises must keep pace with times, break through the traditional strategic thinking with market as the core fundamentally, according to the current development of external market and strive to respond to changes in the external environment using subjective political strategies, in order to seek better development paths. Especially China's economic development has entered a new normalcy. Enterprises no longer wait for constraints and restrictions from laws and regulations passively. Instead, they use all kinds of political strategies to guide themselves to achieve better development. After legitimacy was introduced, relationship-oriented and transaction-oriented political strategies can produce a profound impact on legitimacy. Legitimacy, in turn, directly acted on economic performance and promoted the positive impact of political strategies on economic performance.

\section{Implications}

In the future development, enterprises must carry out political strategies actively, to enhance their competitive advantages. Also enterprises must influence the government's policy process and create a good external environment. In the long run, they are supposed to integrate two kinds of political strategies and promote the sustainable development of enterprises. More than that, China's market economy system is not very mature yet and the government grasps a large number of critical resources. As a result, enterprises approach the government instinctively. But, in fact, enterprises must ultimately return to market and participate in market competition, so they should have a keep proper distance from politics. No matter how strong political capacity an enterprise has, it shouldn't ignore enhancing its own market capacity. 


\section{Conclusion}

To sum up, from the perspective of legitimacy, formulating feasible corporate political strategies can largely improve economic performance. Therefore, enterprises must strengthen the perfection of political strategies and enhance their comprehensive strength, based on their actual situation.

\section{References}

[1] Hillman A J, Zardkoohi A, Bierman L. Corporate political strategies and firm performance: indications of firm-specific benefits from personal service in the U.S. government[J]. Strategic Management Journal, 2015, 20(1):67-81.

[2] Chiu S C, Sharfman M. Legitimacy, Visibility, and the Antecedents of Corporate Social Performance: An Investigation of the Instrumental Perspective[J]. Journal of Management, 2011, 37(6):1558-1585 